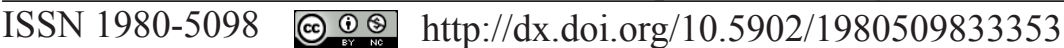

\title{
MEIO AMBIENTE E CIDADES - ÁREAS DE PRESERVAÇÃO PERMANENTE (APPS) MARGINAIS URBANAS NA LEI FEDERAL N. 12.651/12
}

\author{
ENVIRONMENT AND CITIES - URBAN MARGINAL PERMANENT PRESERVATION \\ AREAS ACCORDING TO LAW 12.651/12
}

\author{
Stéphanie Louise Inácio Castro ${ }^{1}$ Leda Ramos $\mathrm{May}^{2}$ Carlos Mello Garcias ${ }^{3}$
}

\begin{abstract}
RESUMO
A revogação do Código Florestal Brasileiro pela Lei Federal no 12.651 (BRASIL, 2012b) gerou grandes polêmicas no país e trouxe importantes modificações sobre diversos temas. No âmbito urbano considerase essencial a visão das novas disposições quanto às áreas de preservação permanente (APPs), importante mecanismo de proteção ambiental. Neste artigo foi realizada a análise da Lei Federal n ${ }^{\circ} 12.651$ (BRASIL, 2012b) em relação às APPs urbanas, ressaltando-se as modificações em relação ao Código Florestal de 1965, e buscou-se apresentar considerações quanto às obras de canalização e retificação dos rios urbanos. Verificaram-se avanços e retrocessos nos novos dispositivos e a necessidade de regulação no tocante às modificações de corpos hídricos.
\end{abstract}

Palavras-chave: Código Florestal; vegetação ripária; mata ciliar urbana; rios urbanos.

\begin{abstract}
The repeal of the Brazilian Forest Code, Law 4.771 (BRASIL, 1965), by the Law 12.651 (BRASIL, 2012b) generated great controversies in the country and brought important changes on various topics. In urban areas, it is essential the vision of new provisions concerning the establishment of Permanent Preservation Areas (PPAs), an important mechanism of environmental protection. In this article, the Law 12.651 (BRASIL, 2012b) was analyzed in relation to urban PPAs, emphasizing changes in relation to 1965 Forest Code, and introducing considerations about channeling and rectification of urban rivers. Some advances and setbacks were noticed in the new legislation as well as the need to control changes in watercourses within urban areas.
\end{abstract}

Keywords: Brazilian Forest Code; urban riparian forest; urban rivers.

\section{INTRODUÇÃO}

A preocupação com a conservação das florestas brasileiras fez com que, em 1934, fosse instituído o primeiro código florestal brasileiro. A necessidade de mudanças e atualização resultou no Código florestal de 1965, instituído pela Lei Federal no 4.771 (BRASIL, 1965), que sofreu importantes modificações em 1989 e uma reforma profunda em 2001. Recentemente, esse código foi revogado pela Lei Federal $\mathrm{n}^{\circ} 12.651$ (BRASIL, 2012b), que dispõe sobre a proteção da vegetação nativa, e que, apesar de revogar sem substituir o Código florestal de 1965, ficou conhecida como 'Novo Código florestal'. Essa nomenclatura, embora imprecisa, é utilizada neste trabalho devido a sua popularidade.

Todas essas leis tiveram por objetivo regulamentar o uso da terra para proteger o patrimônio florestal do país. Um dos instrumentos utilizados para essa proteção é a definição das áreas de preservação permanente (APPs) que, por sua função ambiental relevante, devem ser mantidas e cujo uso, em situações

1 Engenheira Ambiental, Mestre em Gestão Urbana, Pontifícia Universidade Católica do Paraná, Rua Imaculada Conceição, 1155, Prado Velho, CEP 80215-901, Curitiba (PR), Brasil.s_louise@hotmail.com

2 Advogada, MSc., Professora na Pontifícia Universidade Católica do Paraná, Rua Imaculada Conceição, 1155, Prado Velho, CEP 80215-901, Curitiba (PR), Brasil. leda@feresmay.adv.br

3 Engenheiro Civil, Dr., Professor na Pontifícia Universidade Católica do Paraná, Rua Imaculada Conceição,

1155, Prado Velho, CEP 80215-901, Curitiba (PR), Brasil. carlos.garcias@pucpr.br

Recebido para publicação em 23/10/2013 e aceito em 12/05/2017

Ci. Fl., v. 28, n. 3, jul. - set., 2018 
claramente caracterizadas como de excepcionalidade, tem que atender a diversas premissas. A lei de 2012, além de trazer a definição das áreas de preservação permanente, deixa claro que elas agora existem tanto no meio urbano quanto no meio rural.

O cuidado em incluir, de maneira explícita, as zonas urbanas é pertinente, já que as cidades brasileiras se formaram, em sua maioria, ignorando as APPs, sendo marcante a ausência total de faixas de proteção na parte urbana dos rios. Essa ausência era, de certa forma, justificada pelo grande embate que existia quanto à aplicação ou não do Código florestal de 1965 no ambiente urbano, devido a interpretações distintas dadas ao parágrafo único do artigo $2^{\circ}$. Essa indefinição quanto à aplicação ou não e de que forma deveria ser feita nas áreas urbanas acarretou a ocupação generalizada das APPs urbanas. Pelas deficiências na redação da Lei Federal n $n^{\circ} 4.771$ (BRASIL, 1965), estas ocupações puderam ser legalizadas. Com a Lei Federal n ${ }^{\circ} 12.651$ (BRASIL, 2012b) essa dúvida foi eliminada, sendo claramente estabelecido, em seu artigo $4^{\circ}$, que as definições e os limites das APPs valem tanto para as áreas rurais quanto para as áreas urbanas. Além disso, o Código de 2012 não isenta as cidades de recomporem suas APPs degradadas - exceto nas situações previstas na Lei Federal no 11.977 (BRASIL, 2009), que dispõe sobre o programa Minha Casa, Minha Vida - e, assim, para ser integralmente cumprida, as APPs urbanas teriam que ser desocupadas e recuperadas.

Dentre as categorias de APPs constantes da Lei Federal $n^{\circ} 12.651$ (BRASIL, 2012b), foram escolhidas como foco deste trabalho aquelas relativas às margens dos rios, por se considerar este o tipo de APP mais comum na maioria das cidades.

Este trabalho se propõe a realizar uma análise das disposições da Lei Federal n ${ }^{\circ} 12.651$ (BRASIL, 2012b) quanto às APPs urbanas, verificando as mudanças em relação ao Código florestal de 1965. É trazida ainda uma visão sucinta sobre os rios urbanos e sua importância e considerações quanto ao incentivo ou coibição das obras de canalização e retificação dos cursos d'água nas cidades.

\section{DESENVOLVIMENTO}

A edição da Lei Federal $n^{0} 12.651$ (BRASIL, 2012b) foi alvo de diversas críticas e polêmicas, sendo muito defendida por alguns e completamente rejeitada por outros. Por ser objeto de tamanha atenção, o 'Novo Código florestal', como acabou por ser apelidada a Lei de proteção à vegetação nativa, foi bastante discutido nos meios de comunicação. Toda polêmica não contemplou, de forma significativa, as disposições quanto às áreas de preservação permanente. $\mathrm{O}$ novo dispositivo trouxe, porém, importantes mudanças quanto a esse assunto. Destaca-se que, por ser bastante recente, pouco material foi publicado sobre o Código de 2012, utilizando-se parcialmente neste trabalho referências relativas ao Código de 1965, adaptadas para o disposto na Lei Federal n 12.651 (BRASIL, 2012b).

Além da análise dos dispositivos da lei, é interessante, para aprofundamento da discussão, a compreensão das APPs como instituto legal e a visão da importância dos rios urbanos para as cidades brasileiras.

\section{RIOS URBANOS NO BRASIL}

Os rios sempre tiveram importância para as populações humanas, que buscavam se estabelecer próximas aos cursos d'água para usufruírem de seus benefícios. Pitombeira (2006) comenta que as cidades, na maioria das vezes, formaram-se e desenvolveram-se em decorrência da existência de algum curso d'água, seja pelo suprimento de água para as necessidades domésticas, para assegurar o desenvolvimento de atividades produtivas ou por serem meios de transporte e de comunicação. A autora exemplifica que, no Brasil, quase todas as capitais possuem importantes rios associados à sua imagem, como o Rio Negro em 
Manaus, o Guamá em Belém, o Parnaíba em Teresina, o Capibaribe e Beberibe em Recife, o Tietê em São Paulo, o Guaíba em Porto Alegre e o Rio Belém em Curitiba.

Em uma visão fortemente urbanística, Menezes (2007) afirma que, no espaço urbano, o rio torna-se um elemento integrante da paisagem e, em geral, os moradores o adotam como símbolo do lugar: "Quando um rio atravessa a zona central de uma cidade, ele se incorpora à paisagem urbana e ao imaginário coletivo. A construção desse imaginário remete-se frequentemente à função do rio na fundação da cidade e o papel por ele desempenhado na viabilização do crescimento econômico local”.

Ainda segundo a autora, apesar dessa saudável identificação, a expansão da cidade e as modificações no uso e ocupação do solo urbano impactam fortemente o ambiente natural. Muitas vezes, as margens tornam-se objeto de intervenções para formação do eixo viário principal que se aproveita da topografia plana dessas áreas. Há casos muito comuns em que o rio desaparece da paisagem da cidade, quando seu leito é recoberto para construção de vias. Assim, dependendo do planejamento, essas regiões podem se tornar espaços de intenso uso público nas cidades ou, não recebendo tratamento paisagístico adequado, resultar em elementos esquecidos e maltratados no cenário urbano.

Menezes (2007) lembra ainda que a deterioração do ambiente pode ocasionar e produzir espaços deteriorados. Essa desvalorização faz com que a população rejeite as áreas degradadas, o que normalmente acarreta a invasão de terras pela parcela sem opções de moradia.

Escrevendo sobre os rios de Fortaleza, mas de modo totalmente aplicável a diversos casos, Pitombeira (2006) lamenta:

Vê-se a cidade crescendo de modo assustador, sufocando impiedosamente esses rios como se eles não tivessem nenhuma importância para o cenário ambiental da urbe. E isso é flagrantemente constatado, ora ao verificar-se a constante confinação desses cursos d'água em exíguos e humilhantes canais tubulares ou galerias pluviais, ou transformando-os em esgotos a céu aberto.

De forma semelhante, Séguim, Kligerman e Assumpção (2006) afirmam que o desenvolvimento urbano em geral ignora os pequenos cursos d'água que cortam as cidades e, quando os gestores os notam, é para canalizá-los ou cobri-los com a justificativa da necessidade de mais espaço para circulação. Segundo as autoras, para promoção de melhorias, as edificações dentro da faixa de proteção deveriam ser removidas e a mata ciliar recuperada. Porém, esta não é a posição dominante nos Tribunais Superiores, quando se privilegia o direito de propriedade.

Quanto à canalização, tão criticada nos trabalhos citados, deve-se ainda acrescer-lhe a transposição e a retificação de cursos d'água. Garcias (2013) expõe alguns dos problemas ambientais, sociais e paisagísticos causados por esse tipo de obra, em especial, as canalizações subterrâneas:

a) altera o sistema natural;

b) impede a proliferação de fauna macroscópica nas águas;

c) priva os cidadãos dos benefícios do contato com a natureza;

d) impede a incorporação do rio no imaginário cultural urbano;

e) prejudica a macrodrenagem;

f) acelera o escoamento das águas superficiais;

g) reduz o tempo de concentração da bacia hidrográfica;

h) transfere carga hidráulica para jusante;

i) concentra fluxos de água;

j) provoca/intensifica processos erosivos à jusante do canal;

k) provoca/intensifica inundações à jusante;

1) prejudica moradores de áreas à jusante;

m) aumenta o risco de acidentes, como os afogamentos causados pela maior velocidade das águas.

Alguns dos problemas citados são consequências diretas da modificação do corpo hídrico e, assim, geram outros problemas, principalmente no tocante à drenagem. Ao se retirarem os meandros de um curso d'água e reduzir o atrito com as suas margens e fundo, com o emprego de materiais como o concreto, aumenta-se a velocidade das águas, gerando os problemas citados nas letras $\mathrm{g}$, h e i. A soma desses causa o aumento dos processos erosivos e as inundações à jusante, já que as águas chegam em maior quantidade e 
velocidade, prejudicando os moradores de tais áreas e potencializando acidentes em águas rápidas.

\section{ÁREAS DE PRESERVAÇÃO PERMANENTE}

O conceito de área de preservação permanente é relativamente recente. A Lei Federal $n^{\circ} 4.771$ (BRASIL, 1965) (Código florestal) originalmente, não trazia definição, apenas indicava, diretamente em seu artigo $2^{\circ}$, quais áreas eram consideradas como de preservação permanente. Para Franco (2003), a falta de uma definição clara causava discussões doutrinárias e judiciais sobre o que era, ou não, objeto de proteção da lei. Nessas discussões, incluíam-se áreas degradadas, sem vegetação, ou áreas com monoculturas e espécies exóticas. Essa situação foi modificada pela medida provisória (MP) 2.166-67/01 (BRASIL, 2001)

Milaré (2011) destaca dessa modificação a intenção clara do legislador de proteger não só a vegetação, mas os locais e formações geográficas e Machado (2012) defende que a vegetação e a área são objeto de proteção não por si mesmas, mas pela sua função de proteger a água, o solo e a biodiversidade. Brandão (2001) afirma que, antes da definição dada por essa MP, muitos autores entendiam que somente as florestas e demais formas de vegetação situadas nas áreas delimitadas - e não as áreas em que elas se localizavam - eram de preservação permanente. Para esses, estando sem cobertura vegetal, as áreas poderiam sofrer qualquer tipo de intervenção humana, sem obrigatoriedade de recuperação ou preservação.

A definição dada em 2001 foi integralmente mantida na Lei Federal nº 12.651 (BRASIL, 2012b), sendo apresentada no seu artigo $3^{\circ}$, Inciso II:

Área de Preservação Permanente - APP: área protegida, coberta ou não por vegetação nativa, com a função ambiental de preservar os recursos hídricos, a paisagem, a estabilidade geológica e a biodiversidade, facilitar o fluxo gênico de fauna e flora, proteger o solo e assegurar o bem-estar das populações humanas.

Legalmente, percebem-se duas tipologias distintas de APP, dependendo do meio pelo qual ela é instituída. Primeiramente, têm-se as APPs definidas no artigo $4^{\circ}$ da Lei Federal n ${ }^{\circ} 12.651$ (BRASIL, 2012b), em seus 11 incisos. Cada uma das categorias ali criadas tem suas especificidades definidas e são consideradas passíveis de proteção, em especial, pela sua localização. Todas as áreas de proteção definidas no artigo $4^{\circ}$ são de preservação permanente pelo só efeito da lei, não sendo necessários atos adicionais que as qualifiquem como tal (BRASIL, 2012b). Adaptando as afirmações de Franco (2003) sobre o Código de 1965, pode-se afirmar que somente com a leitura da lei é possível identificar diferentes subgrupos dentro das categorias apresentadas, identificáveis pelos espaços que se destinam a proteger. Os subgrupos identificados pelo autor são:

a) margens dos rios - na versão de 2012, os cursos d'água naturais, perenes ou intermitentes possuem as margens protegidas (Inciso I);

b) entorno de lagoas, lagos e reservatórios - lagoas e lagos naturais possuem faixas de preservação variando de 30 a 100 metros de largura, a depender de sua localização e área superficial (Inciso II). A faixa de preservação dos reservatórios artificiais deve ser definida no processo de licenciamento ambiental (Inciso III);

c) as nascentes - as nascentes e olhos d'água perenes possuem APP com raio mínimo de 50 metros (Inciso IV);

d) as encostas e topo de morros - as encostas - ou partes dessas - com declividade superior a $45^{\circ}$ devem ser protegidas (Inciso V), bem como o topo de morros, montes, montanhas e serras, com características definidas na lei (Inciso IX);

e) as áreas de restingas, manguezais, veredas, bordas de tabuleiros e chapadas e aquelas situadas em altitude superior a $1.800 \mathrm{~m}$ - diversas áreas que devem ser protegidas devido à elevada vulnerabilidade desses ecossistemas (Incisos VI, VII, VIII, X e XI).

A lei também apresenta, em seu artigo $6^{\circ}$, a possibilidade de áreas adicionais serem definidas como de preservação permanente, quando declaradas de interesse social por ato do Presidente da República, do 
Governador ou do Prefeito Municipal. As áreas passíveis desta tipificação são as que possuem florestas ou outras formas de vegetação destinadas às finalidades seguintes, algumas comentadas por Figueiredo (2005):

a) conter a erosão do solo, reduzir riscos de enchentes e deslizamentos de terra - as matas relacionadas no artigo $4^{\circ}$ também possuem essa finalidade; porém, incluindo-as também no artigo $6^{\circ}$, a lei possibilita que sejam consideradas outras situações onde haja necessidade técnica de proteção da vegetação;

b) proteger as restingas ou veredas;

c) proteger várzeas;

d) abrigar exemplares da fauna ou da flora ameaçados de extinção - essa hipótese pouco difere da criação de um Refúgio da Vida Silvestre;

e) proteger sítios de excepcional beleza ou de valor científico, cultural ou histórico - em geral esses sítios são protegidos por meio da criação de unidades de conservação ou tombamento;

f) formar faixas de proteção ao longo de rodovias e ferrovias - hipótese mais relacionada à garantia do bem-estar das populações humanas do que à preservação da biodiversidade;

g) assegurar condições de bem-estar público - hipótese aberta para exercício do poder discriminatório da administração;

h) auxiliar a defesa do território nacional, a critério das autoridades militares;

i) proteger áreas úmidas, especialmente as de importância internacional.

Salienta-se ainda que, embora a definição das áreas passíveis de proteção na Lei Federal no 12.651 (BRASIL, 2012b) seja semelhante a da Lei Federal $n^{\circ} 4.771$ (BRASIL 1965), esta era regulamentada por três resoluções do Conselho Nacional de Meio Ambiente (CONAMA): Resolução $n^{\circ}$ 302/02, que dispõe sobre as APPs de reservatórios artificiais; a Resolução 303/02, que define parâmetros e limites para APPs; e a Resolução 369/06, que possibilita a intervenção nas APPs (CONSELHO NACIONAL DO MEIO AMBIENTE, 2002a; 2002b, 2006). Com a edição da Lei Federal no 12.651 (BRASIL, 2012b), não há consenso quanto à atual vigência dessas resoluções. Porém, já que os parâmetros estão hoje fixados nesta lei, que é hierarquicamente superior às resoluções, todas as disposições que a contrariam foram revogadas. Resta ainda a dúvida quanto à Resolução 369/06, mas não havendo disposições na nova Lei quanto à supressão (exceto para casos de regularização fundiária), esta norma poderia continuar sendo aplicada.

Dentre as APPs apresentadas, foram escolhidas como foco deste trabalho aquelas enquadradas no primeiro grupo, instituídas pelo artigo $4^{\circ}$ da Lei Federal $n^{\circ} 12.651$ (BRASIL, 2012b) e, no primeiro subgrupo, relativo às margens dos rios, por se considerar o tipo de APP mais comum na maioria das cidades.

Quanto à metragem das faixas desse grupo de APPs, muito se discute quanto ao embasamento utilizado. Sobre as mudanças ocorridas no Código de 1965, em 1986, Ancona (2007) afirma que "os critérios técnicos para adoção dos novos parâmetros nunca foram apresentados e muito menos foi justificada a suposição de que eles eram igualmente adequados para áreas urbanas e rurais". A opinião da autora reflete o descontentamento de muitos com a definição arbitrária dos dispositivos do código florestal de 1965.

Nesse sentido, pode-se citar o trabalho de Metzger (2010), que procurou responder às questões ligadas ao Código de 1965, entre elas a largura das faixas de APP, com o objetivo de verificar se o avanço da ciência sustentava ou não as premissas do referido dispositivo legal. Com base em dados obtidos por trabalhos em diferentes biomas brasileiros, o autor conclui que corredores de apenas 30 metros têm capacidade muito limitada de manutenção da biodiversidade. Para ele, o conhecimento científico obtido nos últimos anos permite, não apenas sustentar os valores indicados, mas apontam para a necessidade de expansão destes valores para limiares mínimos de pelo menos 100 metros (50 metros de cada lado do rio), independentemente do bioma, do grupo taxonômico, do solo ou do tipo de topografia.

\section{O CÓDIGO FLORESTAL DE 1965 E A LEI DE PROTEÇÃO À VEGETAÇÃO NATIVA DE 2012}

O capítulo II da Lei Federal $n^{\circ} 12.651$ (BRASIL, 2012b), trata exclusivamente das áreas de preservação permanente, sendo que o seu artigo $4^{\circ}$ define quais áreas são de preservação permanente e possui 11 incisos que as discriminam. $\mathrm{O}$ inciso de interesse para este trabalho está transcrito abaixo, assim 
como o caput do artigo $4^{\mathrm{o}}$ :

Art. $4^{\circ}$ Considera-se Área de Preservação Permanente, em zonas rurais ou urbanas, para os efeitos desta Lei:

I - as faixas marginais de qualquer curso d'água natural perene e intermitente, excluídos os efêmeros, desde a borda da calha do leito regular, em largura mínima de: de largura;

a) 30 (trinta) metros, para os cursos d'água de menos de 10 (dez) metros

b) 50 (cinquenta) metros, para os cursos d'água que tenham de 10 (dez) a 50 (cinquenta) metros de largura;

c) 100 (cem) metros, para os cursos d'água que tenham de 50 (cinquenta) a 200 (duzentos) metros de largura;

d) 200 (duzentos) metros, para os cursos d'água que tenham de 200 (duzentos) a 600 (seiscentos) metros de largura;

e) 500 (quinhentos) metros, para os cursos d'água que tenham largura superior a 600 (seiscentos) metros (BRASIL, 2012b, grifo nosso).

Com esse artigo fica claramente definida a existência das APPs em áreas urbanas, valendo para estas exatamente os mesmos limites impostos para as áreas rurais. Embora o inciso I do artigo $4^{\circ}$ mencione cursos d'água perenes, intermitentes e efêmeros, a Lei n ${ }^{\circ} 12.651$ (BRASIL, 2012b) não traz a conceituação dessas tipologias. Essa lacuna prejudicava a interpretação por não haver conceitos formalizados legalmente. No entanto, no mesmo ano foi publicada a Resolução $\mathrm{n}^{\circ} 141$ do Conselho Nacional de Recursos Hídricos (2012) e o Decreto $n^{0} 7830$ (BRASIL, 2012a), tratando dos conceitos de forma idêntica:

I - rios intermitentes: corpos de água lóticos que naturalmente não apresentam escoamento superficial por períodos do ano;

II - rios efêmeros: corpos de água lóticos que possuem escoamento superficial apenas durante ou imediatamente após períodos de precipitação;

III - rios perenes: corpos de água lóticos que possuem naturalmente escoamento superficial durante todo o período do ano (BRASIL, 2012a; CONSELHO NACIONAL DE RECURSOS HÍDRICOS, 2012).

Quanto à metragem, é interessante a comparação com as versões anteriores do Código florestal, apresentada na TABELA 1. Deve-se ter o cuidado de não avaliar isoladamente a largura da faixa, mas considerar também a referência da medição. A faixa, antes medida a partir do nível mais alto atingido durante a cheia do curso d'água, passou a ser medida a partir da borda do leito regular, sendo desconsiderada a variação sazonal. 
TABELA 1: Largura da faixa de preservação permanente de cursos d'água.

TABLE 1: Width of the permanent preservation area of watercourses.

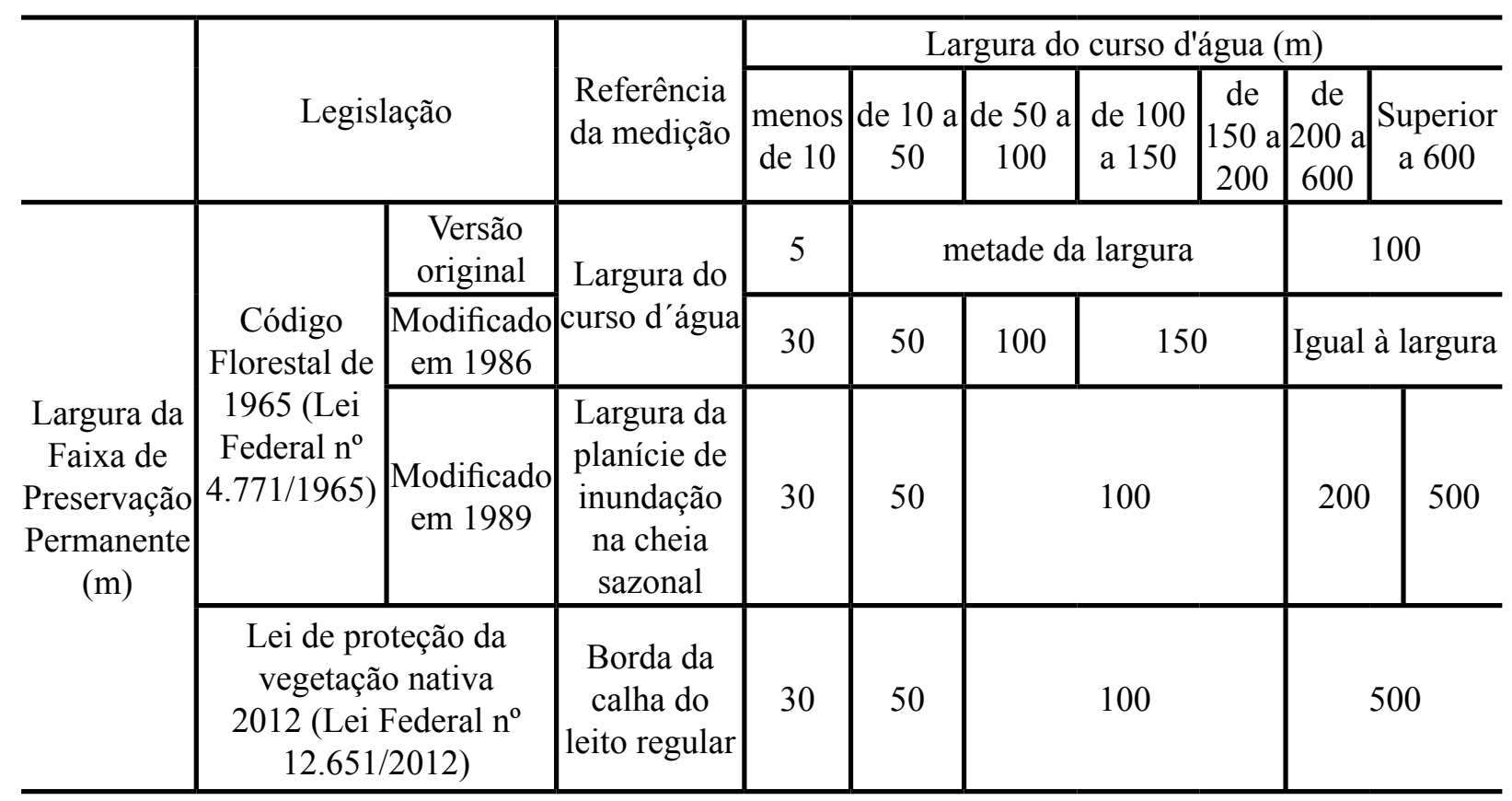

Fonte: Adaptado de Ramos e Ahmad (2012).

Além do Artigo $4^{\circ}$, outros relacionados às APPs e às zonas urbanas são:

a) Artigo $7^{\circ}$ - É obrigatória a recomposição [das APPs], exceto em caso de usos autorizados pela lei.

b) Artigo $8^{\circ}$ - A supressão pode ser autorizada em caso de utilidade pública, interesse social ou atividades de baixo impacto.

c) Artigos 64 e 65 - Possibilidade de regularização fundiária de assentamentos, de interesse social e interesse específico situados em APP, regulamentada pela Lei Federal n $\mathrm{n}^{\mathrm{o}} 11.977$ (BRASIL, 2009). No caso de regularização por interesse específico deve ser mantida faixa não edificável de 15 metros ao longo dos cursos d'água. (BRASIL, 2012b).

A referida lei dispõe sobre o Programa Minha Casa, Minha Vida do Governo Federal, considerada um marco na questão da regularização fundiária urbana, que traz as definições:

a) Regularização Fundiária de Interesse Social: regularização fundiária de assentamentos irregulares ocupados por população de baixa renda nos casos de usucapião ou zonas específicas de interesse social.

b) Regularização Fundiária de Interesse Específico: regularização fundiária quando não caracterizado o Interesse Social (BRASIL, 2009).

\section{MODIFICAÇÕES TRAZIDAS PELA LEI FEDERAL No 12.651/12}

Em relação às APPs urbanas, a Lei Federal no 12.651 (BRASIL, 2012b) trouxe grande avanço com a definição clara de sua existência e limites idênticos aos das APPs rurais. Apesar disso, autores como Ramos e Ahmad (2012) e Fernandes (2012) afirmam que essa lei fragilizou a proteção ambiental com certas mudanças, possibilitando maior degradação ambiental em áreas antes protegidas. Fernandes (2012) sustenta que, em relação ao Código Florestal de 1965, as modificações introduzidas pela Lei Federal $\mathrm{n}^{\circ}$ 12.651 (2012b) "contrariam frontalmente as disposições constitucionais que tratam das obrigações do Poder Público para dar efetividade ao meio ambiente ecologicamente equilibrado", além de colocarem em risco o bem-estar da população. Dentre as modificações, destacam-se três, constantes do inciso I, Artigo $4^{\circ}$, 
cujo impacto é considerado mais significativo.

A primeira delas não chega a ser uma modificação; porém, abre uma brecha na lei ao considerar que são APPs as faixas marginais de qualquer curso d'água natural. Este termo, introduzido no corpo do inciso I, poderá levar à interpretação de que cursos d'água modificados com canalizações, retificações, desvios de curso ou transposições são cursos d'água não naturais e, assim, não passíveis de proteção com faixa marginal. A maior parte dos rios urbanos é modificada em pelo menos uma dessas formas, de modo que, a depender da interpretação, nas áreas urbanas praticamente inexistem cursos d'água naturais.

Outra modificação é a exclusão dos cursos d'água efêmeros. Essa exclusão implica dois problemas principais: em geral, as cartas oficiais não diferenciam rios efêmeros dos demais, demandando esforços suplementares para sua identificação e ampliando a margem de erro por confusão entre os conceitos de curso intermitente e curso efêmero. Além disso, os cursos d'água efêmeros são abundantes em zonas áridas, como o nordeste brasileiro, e nessas zonas sua proteção adquire importância social e ambiental.

Por fim, a terceira mudança advinda desse Inciso: a modificação da referência de medição da faixa de proteção. O Código de 1965, a partir das modificações introduzidas pela Lei Federal n ${ }^{0}$ 7.803/89, determinava que a largura fosse medida a partir do nível mais alto do curso d'água, enquanto o Código de 2012 define que a referência é a borda da calha do leito regular, também chamada de leito menor (BRASIL, 1989; 2012b). Ramos e Ahmad (2012) afirmam que, com a mudança, a faixa de proteção passou a ser locada no que se entende como o próprio corpo d'água. Segundo essas autoras, o leito do rio não compreende apenas o local cujas águas correm regularmente, mas varia sazonalmente em função das chuvas. A Figura 1 ilustra esse conceito, comparando a faixa de APP segundo o Código de 1965 e a Lei Federal $n^{\circ} 12.651$ (BRASIL, 2012b). Percebe-se que, com a modificação de referência, a faixa de proteção passa a ser parcialmente locada dentro do leito maior do rio, que é naturalmente ocupado pelas águas em períodos de cheia.

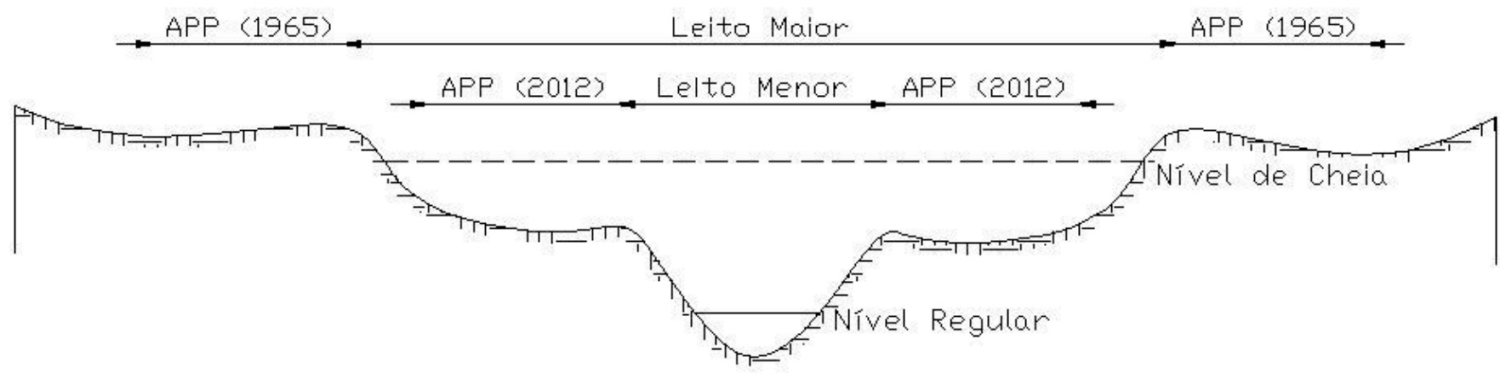

Fonte: Adaptado de Ramos e Ahmad (2012)

FIGURA 1: Comparação das referências para determinação da largura da faixa de APP às margens de curso d'água. FIGURE 1: Comparison between the two criteria for determing the width of the riparian protection buffer.

Além das modificações apresentadas, diversas questões não foram elucidadas na Lei $\mathrm{n}^{\circ} 12.651$ (BRASIL, 2012b), deixando falhas legais que podem facilitar a degradação do ambiente urbano. Por exemplo, não foi definido como deve ser considerado um curso d'água canalizado, situação bastante comum nos meios urbanos. Também não foram consideradas as situações de retificação de rios e modificações no curso, casos em que geralmente as APPs acabam sendo reduzidas ou até mesmo inteiramente suprimidas.

\section{CONSIDERAÇÕES FINAIS}

Quanto à visão geral do instituto das APPs, percebe-se uma evolução quanto ao bem tutelado. No Código Florestal de 1934, os bens tutelados eram as áreas em que se encontravam as florestas (BRASIL, 1934). No Código de 1965, as florestas somente eram protegidas pela sua utilidade para garantir o abastecimento de água e evitar erosões, em uma visão estritamente utilitarista. A partir da Medida Provisória 2.166-67/01, na definição mantida pela Lei Federal $n^{\circ} 12.651$ (BRASIL, 2012b), a proteção passa a ter caráter mais amplo, protegendo não somente a floresta, mas também mantendo importantes serviços ecossistêmicos, como a proteção da biodiversidade e do fluxo gênico.

Percebe-se, no Código Florestal de 2012, a preocupação em assegurar a existência de APPs em 
áreas urbanas, ainda que com certa flexibilização no regime de proteção dessas áreas. Essa flexibilização pode ser vista no inciso I do Artigo $4^{\circ}$, que modifica a referência para determinação da largura da faixa de preservação permanente, exclui os cursos d'água efêmeros e define que os cursos d'água naturais perenes ou intermitentes são os únicos a possuírem a faixa de preservação.

Apesar dos avanços consideráveis, faltam ainda conceitos legais relativos à nova disposição de APPs em áreas urbanas. A ausência do conceito claro do que é um rio urbano, seja em lei ou resolução normativa, prejudica a aplicação da lei, podendo gerar interpretações contrárias ao objetivo de proteção ambiental. Falta também regulamentação quanto aos cursos d'água modificados com retificações ou canalizações. Nas obras de canalização, retificação e transposição, frequentes nas áreas urbanas, em geral não são consideradas as áreas de preservação permanente, que, via de regra, acabam suprimidas. Com a falta de regulamentação clara, podem surgir interpretações de que um corpo d'água canalizado perde seu status de rio e, assim, não necessita de APP.

No que se refere às zonas urbanas, pode-se inferir que a intenção da Lei Federal n ${ }^{\circ} 12.651$ (BRASIL, 2012b) é claramente evitar a geração de novos problemas ambientais, não se encontrando evidências de que seria intenção do legislador incentivar as obras de modificação dos trechos urbanos dos cursos d'água. Assim, defende-se a obrigatoriedade de áreas de preservação permanente em cursos d'água canalizados, coibindo as práticas de canalizações desnecessárias, mantendo-se a APP tanto no curso do leito original com seus meandros quanto no novo curso retificado.

Percebe-se um grande distanciamento entre o disposto na lei e a realidade das cidades brasileiras. As margens dos rios são em geral inteiramente ocupadas e urbanizadas, muitas vezes aproveitando-se a topografia suave das margens para a malha viária. Tendo em vista a dimensão do desafio de renaturalizar as margens dos rios urbanos, deve-se então repensar o regime de proteção das mesmas. Muitas soluções de regularização fundiária e renovação urbanística têm sido aprovadas desconsiderando a intocabilidade das APPs e assim, desrespeitando a lei de proteção da vegetação nativa.

Por esse cenário, considera-se pertinente o contínuo debate sobre o regime de proteção das APPs às margens de rios situados em zonas urbanas, para efetividade da proteção ambiental e bem-estar social que essas deveriam representar nas cidades, não relegando as disposições dadas pelo Código Florestal desde 1934 ao eterno descumprimento.

\section{REFERÊNCIAS}

ANCONA, A. L. APPs em áreas urbanas x direito à moradia. In: SEMINÁRIO APP URBANA, 1., 2007, São Paulo. Resumos... São Paulo: FAUUSP, 2007. p. 235-237.

BRANDÃO, J. C. L. Aspectos jurídicos das florestas de preservação permanente e das reservas legais: proteção ambiental e propriedade. Revista de Direito Ambiental, São Paulo, n. 21, p 114-146, jan./mar. 2001.

BRASIL. Decreto $\mathbf{n}^{0}$ 23.793, de 23 de janeiro de 1934. Disponível em: <http://www.planalto.gov.br/ ccivil_03/leis/L4771.htm>. Acesso em: jan. 2013.

BRASIL. Lei $n^{0}$ 4.771, de 15 de setembro de 1965. Disponível em: <http://www.planalto.gov.br/ccivil_03/ leis/L4771.htm>. Acesso em: jan. 2013.

BRASIL. Lei $\mathbf{n}^{0}$ 7.803, de 18 de julho de 1989. Disponível em: <http://www.planalto.gov.br/ccivil_03/ leis/L7803.htm>. Acesso em: jan. 2018.

BRASIL. Medida Provisória n ${ }^{\circ}$ 2.166-67, de 24 de agosto de 2001. Disponível em: < http://www.planalto. gov.br/ccivil_03/mpv/2166-67.htm>. Acesso em: fev. 2013.

BRASIL. Lei no 11.977, de 07 de julho de 2009. Disponível em: <http://www.planalto.gov.br/ccivil_03/_ ato2007-2010/2009/lei/111977.htm>. Acesso em: fev. 2013.

BRASIL. Decreto no 7.830, de 17 de outubro de 2012a. Disponível em: <http://www.planalto.gov.br/ ccivil_03/Ato2011-2014/2012/Decreto/D7830.htm>. Acesso em: maio 2017.

BRASIL. Lei no 12.651, de 25 de maio de 2012b. Disponível em: < http://www.planalto.gov.br/ccivil_03/_ Ato20112014-2012/Lei/L12651.htm>. Acesso em: jan. 2013.

CONSELHO NACIONAL DE RECURSOS HÍDRICOS (Brasil). Resolução $\mathbf{n}^{\mathbf{0}} \mathbf{1 4 1}$, de 10 de julho

de 2012. Disponível em: $<$ http://www.cnrh.gov.br/index.php?option =com_docman\&task=doc_ 
download\&gid $=1633>$. Acesso em: maio 2017.

CONSELHO NACIONAL DO MEIO AMBIENTE (Brasil). Resolução n 302, de 20 de março de $2002 a$. Disponível em: <http://www.mma.gov.br/port/conama/res/res02/res30202.html >. Acesso em: mar. 2013. CONSELHO NACIONAL DO MEIO AMBIENTE (Brasil). Resolução n 303, de 20 de março de $2002 b$. Disponível em: $<$ http://www.mma.gov.br/port/conama/res/res02/res30302.html>. Acesso em: mar. 2013. CONSELHO NACIONAL DO MEIO AMBIENTE (Brasil). Resolução no 369, de 28 de março de 2006. Disponível em: $<$ http://www.mma.gov.br/port/conama/legiabre.cfm?codlegi=489>. Acesso em: mar. 2013. FERNANDES, P. L. P.Análise das principais mudanças que a Lei Federal $\mathbf{n}^{\mathbf{0}} \mathbf{1 2 . 6 5 1 / 1 2}$, de 25 de maio, trouxe ao ordenamento jurídico ambiental. Goiânia: MPGO, 2012. Disponível em: <http://www.mpgo. mp.br/portal/system/resources.

FRANCO, J. G. O. Áreas de preservação permanente: ciliares. 2003. 201 f. Dissertação (Mestrado em Direito Econômico e Social) - Pontifícia Universidade Católica do Paraná, Curitiba, 2003.

GARCIAS, C. M. Sustentabilidade e redução de impactos no meio ambiente. CONFERÊNCIA MUNICIPAL DO MEIO AMBIENTE, 8., 2013, São José dos Pinhais. Anais... [s. 1.: s. n.], 2013.

MACHADO, P. A. L. Direito ambiental brasileiro. São Paulo: Malheiros, 2012.

MENEZES, M. L. P. A cidade e o rio, o rio e a cidade: Espaços para o Público. Scripta Nova, Barcelona, v. 11, n. 245, ago. 2007. Disponível em: <http://www.ub.edu/geocrit/sn/sn-24535.htm>. Acesso em: ago. 2013.

METZGER, J. P.O Código Florestal tem base científica? Conservação e Natureza, São Carlos, v. 8, n. 1, p. 92-99, jul. 2010. Disponível em: <http://www.abeco.org.br/node/26>. Acesso em: fev. 2013.

MILARÉ, E. Direito do ambiente. São Paulo: Revista dos Tribunais, 2011.

PITOMBEIRA, S. C. Nossos Rios, Nossa Responsabilidade. Revista de Direitos Difusos, São Paulo, v. 7 , n. 39, p. 09-19, set./out. 2006.

RAMOS, R. I.; AHMAD, I. T. Código Florestal: apreciação atualizada. São Paulo: ABES-SP, 2012. Disponível em: $<$ http://www.abes-sp.org.br/arquivos/atualizacao_codigo_florestal.pdf $>$. Acesso em: maio 2013.

SÉGUIM, E.; KLIGERMAN, D. C.; ASSUMPÇÃO, R. F. Uma Gestão Sustentável das Águas Urbanas e a Aplicabilidade do Princípio da Precaução - como convive a população urbana e seus rios. Revista de Direitos Difusos, São Paulo, v. 7, n. 39, p. 69-84, set./out. 2006. 